\title{
Construction on Government Assistant Decision System for Urban Public Crisis Management
}

\author{
Yongchang Ren \\ College of Information Science and Technology, Bohai University, Jinzhou, 121013, China
}

1213552916@qq.com

\begin{abstract}
Keywords: urban management; public crisis; government decision-making; assistant decision system; system construction
\end{abstract}

\begin{abstract}
All types of emergencies, mass incidents, accidents, etc. occur frequently, has become a serious factor affecting urban harmony and stability. The government department assistant decision-making system for urban public crisis management is an effective method to improve crisis management level and scientific decision-making. This paper studies the issues related to the decision-making system construction, including the status of crisis decision-making research, the need for system construction, the structure of assistant decision system and so on. Among them, the structure of assistant decision system consist of information management subsystem, the human-machine interface subsystem, the issues addressed subsystems, knowledge management subsystems, etc. Contents of this paper solved the key problems of urban public crisis management government assisted decision system construction, has an important guiding role in the construction and operation of system.
\end{abstract}

\section{Introduction}

Public crisis refers to that seriously threat to the basic values and behavior standard architecture of the social system, and in the situation that extremely high time pressure and uncertainty must make critical decisions for its event. Substance of public crises is that threatening public security and undermines social order and living space, violations of personal safety and property security. Society in a certain historical period cannot eradicate these six curses, inevitably will encounter the public crisis. Deal with public crises, to build a harmonious society and improve social well-being index is extremely important. Assistant decision system, in order to focus on the theme of the decision, basis on the Internet search technology, intelligent information processing technology and natural language processing technology, building the knowledge base related decision thematic studies, policy analysis model library and information research method libraries, building and constantly improving assistant decision system provide all-round, multi-level decision support and knowledge services for decision-making theme. It provides industry research institutions and government department with decision-making basis, and assists policymakers.

The uncertainty of sudden incident breaking out, the severity of the loss and unpredictable nature, the possibility of catastrophic consequences is also growing. Because there are a lot of information and a lot of uncertainty, which makes rational and scientific decision-making become very difficult. For a long time, the emergency management of government for city incident has always stressed that "prevention", when the incident happened, it appear powerlessness, real or imagined [1]. The reason is the theory and method of urban emergency response management is imperfect, the decision-making process depends on people's subjective experience of thinking, lack of effective decision support. This study focus on the characteristics and happened mechanism of urban emergency, designed assistant decision system to address the key issues that the government disposes city emergency management, and improved emergency decision-making level emergencies, reduced accident losses and risk decisions.

\section{Research Status of Crisis Decision-making}

Emergency core processes include prevention and emergency preparedness, monitoring and early 
warning, emergency response and rescue, recovery and reconstruction four stages. Emergency disposed decision-making is a key part throughout the process of emergency management, because the quality of emergency decision-making often directly related to the effectiveness and final loss or impact formed by incident. Currently the research of crisis decision-making for emergency mainly focuses on the following aspects:

(1) In terms of the emergency decision-making model, some scholars reference model for other areas of decision-making incidents were investigated: if the Irish scholar John Cosgrave describes the basic features in emergencies decision problem based on the use of Vroom and Yetton leading theoretical model specification model building emergency decisions, we recommend that the decision makers on the basis of characteristics of the problem, using different decision authorizing the extent of the incident. Kelian will experience military combat decision model is introduced into the emergency decision-making, allowing subordinates in the case of fully understanding the tasks and objectives, based on the experience of the previous assessment of the current environment, based on the experience to find similar response approach to decision-making action program amendments.

(2) In terms of emergency decision-making methods, some of the scholars in the study of emergencies, the use of risk management in the field of applied mathematics and utility analysis, sensitivity analysis, probabilistic analysis of emergency decision made emergencies analysis: as Noel Pauwels et al using utility analysis and sensitivity analysis methods retreat decision nuclear leak incident were analyzed. Hiroyuki Tamura et al., Decision tree analysis of disaster risk analysis. In addition, some scholars use operations research methods, emergency evacuation and retreat occurred after the officers were analyzed. From the point of view of these methods, which are mainly based on the basis of classical decision theory, applied mathematics or borrow risk management theory approach, from the perspective of cost and risk qualitative analysis of existing decisions, to solve a specific outbreak of unexpected events after emergency decision problem.

(3) In the study of emergency decision-making mode, mainly based on statistical analysis of the rational mode, focusing on the decision-making mode satisfaction actual environmental constraints, with the consultation of the progressive group decision-making model. Now commonly used is G.A.Klein proposed RPD decision-making model, decision-making features of the site from the natural disaster emergency decision to proceed to the study, pointed out that decision-makers in a dynamic environment often based on their previous experience, to assess the current environment, based on experience to find similar experience and practice, and make decisions based on the similarity decision-making environment and other conditions. This decision-making model is concerned that the feasibility of the program, and timely decision-making and implementation effect, is a kind of cognitive-based decision-making model, there is a strong environmental adaptability.

\section{Necessity of System Construction}

Public crisis management is not just a responding disposition after event out breaking, since it involves a wide range, needs to deploy and integrate human, financial, material and information resources varied, so from early warning of events, to the final disposal of the recovery must have systems the plan, in order to ensure the accuracy and effectiveness of public crisis management. The necessity of city public crisis government assistant decision-making system construction reflected in the following aspects [2, 3]:

(1) The study and construction of government assistant decision system for urban public crisis is relatively backward. Academia actively carry out research decision support system, and achieved fruitful achievements in government macroeconomic management, industrial planning and management, resource development and utilization of various types of decision-making, but for the city public crisis management support system research is lagging behind. While some places set up an emergency decision support system, but the role in early warning, decision support, and other aspects of post lessons learned little. Most decision support system is now using copy foreign experience, not only spent a lot of manpower, financial and material resources, but also suited to 
China's national conditions. Therefore, research and construction in line with China's national conditions of urban public crisis government assisted support system is very urgent task.

(2) Currently, China various emergency command belong to various government departments, basically their own management, fragmented, self-contained, is the weak link of public crisis management. Once a crisis occurs, there will be long command, coordination difficult situation. Constructed a unified government assistant decision system for public crisis management, integrated resources scattered in various departments into a single platform, the emergency rescue capabilities across all departments integrated into a command and control center. After the crisis occurred, break down departmental boundaries fragmented, rapid coordination department, organization of resources to respond effectively. Therefore, the establishment of urban public crisis management of government decision-making system, the formation of a unified scheduling, joint coordination, and a new mechanism of public crisis management information sharing has particular significance.

(3) Non-procedural and timeliness characteristics for public crisis decision-making, the traditional government crisis decision does not meet the requirements of modern society. Outstanding problems facing the public crisis management, is the relevant information collection, analysis, collation complex, rapidly deal with the problem is difficult to promptly resolve emergencies. In order to meet the objective to solve the crisis of modern public demand, new technologies, and new ways must be sought in the government departments of public crisis decision making. Through advanced information technology, network technology, decision support technology combined with public crisis management theory, the construction of assistant decision system, for the timely collection, compilation, analysis, transmission and processing of all kinds of information, improve ability to control information on the crisis and crisis management government capacity and other aspects have help.

(4) Traditional urban public crisis decision-making methods are simple, lack of scientific methodology guidance. From the government public crisis decision-making practice, it has not implemented the decision from the traditional to the modern scientific decision-making experience changes. Many localities and departments will experience the decision-making as a fundamental way to take the "trial and error" and cannot meet the requirements of crisis decision-making time, there may be greater because of the delay caused by the timing of the crisis. Although the system theory, operations research and computer analysis of the decision-making methods and other new technologies in the theoretical research direction is very mature, but have not really apply to the decision-making practices. Therefore, the integration of all aspects of intelligence inside and outside government, technology, information resources, and set up a government assistant decision system for public crisis management; it is a necessary means to achieve public crisis management.

\section{System Structure of Assistant Decision}

Assistant decision system has four functions, namely: information services, it can be divided into external services and internal services into two categories. External services mainly refers to provide decision makers the information they need, but also can be used as information resources from other systems; internal services is to provide basic data for the other functions are implemented; scientific computing, scientific computing optimization is not, nor is it the other model calculations package, but to calculate the necessary auxiliary decisions made, not the pursuit of this calculation model complexity, and pay attention to user involvement and choice; decision-making advice, based on scientific calculation, after increased functional knowledge and reasoning, we can further support from decision-making role. In order to strengthen the decision-making advisory functions, and sometimes can be developed as a quasi-expert decision support system; artificial intelligence, artificial intelligence support functions is the best decision support, the goal is mainly full of people and machines to interact, to work together to complete The purpose decision tasks. Intelligent assistant decision system can be considered to achieve the highest level of support. The structure of assistant decision system is shown in Fig. 1 [4-6].

As can be seen from Fig. 1, the assistant decision system consists of information management 
subsystem; the human-machine interface subsystem, the issues addressed subsystems and knowledge processing subsystem four sub-systems, the various subsystems are briefly described below:

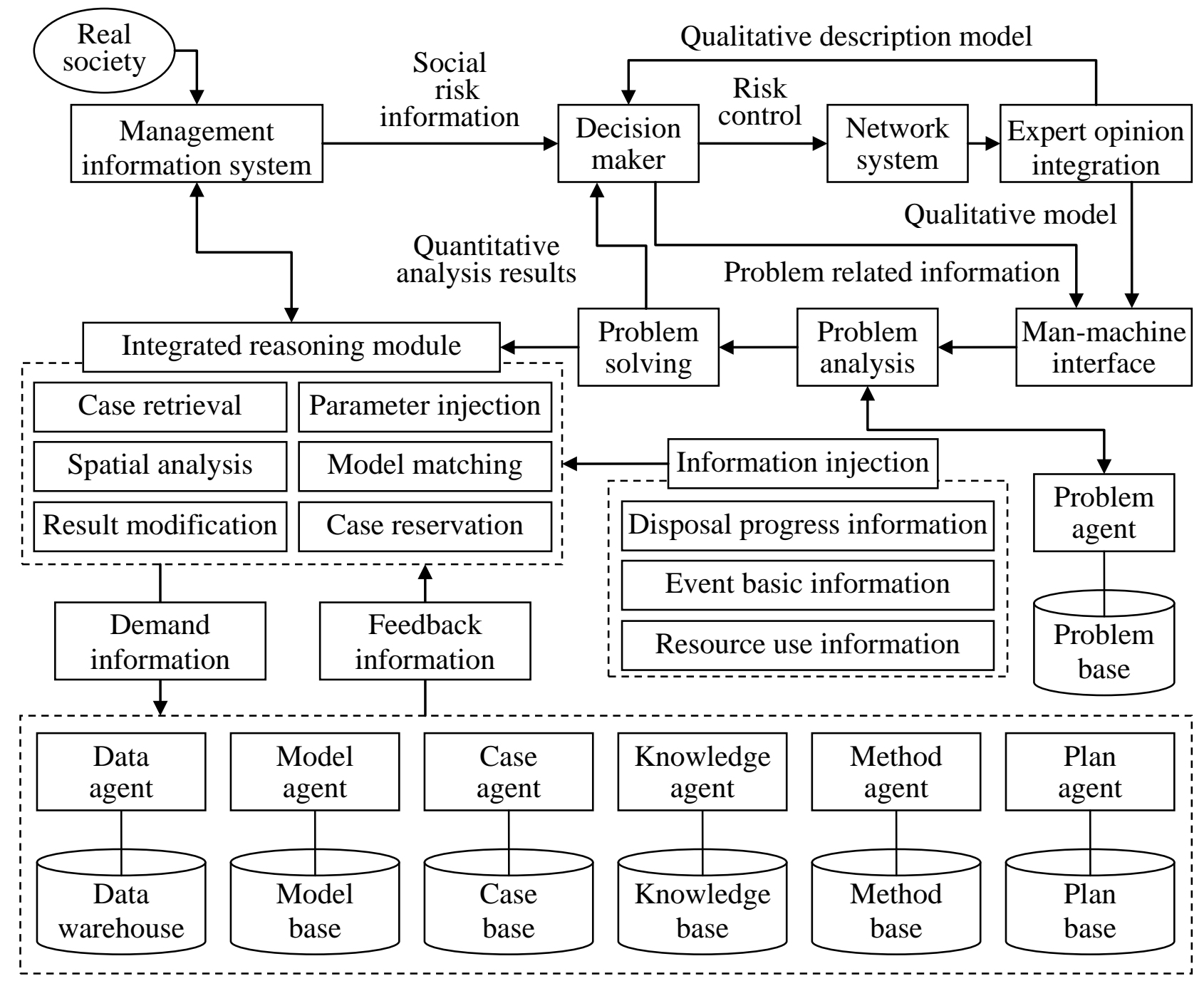

Fig. 1. Structure of assistant decision system for urban public crisis

(1) Information management subsystem. All content information refers to the spread of human society is to provide effective decision-making data is the basis of government crisis decision-making, it is the normal operation of government crisis decision-making mechanism of the media and ties, coordination, control, supervision and an important means of proper implementation of government crisis decision. Relying on reliable sources of information, timely, comprehensive and accurate collection of various departments, major disaster risk information data for each region, a variety of organizations, the media and from countries, and to gather information for unified management of resources, rule out false information. In response to urban sudden public crises, provide a strong guarantee for crisis decision. In the process of information management, to follow the principles that rule out false information and to screen a variety of useful information

(2) The human-machine interface subsystem [7]. Human-machine interface (HMI, Human Machine Interaction), also known as the user interface or the user interface, is transmitted between people and computers, media and dialogue interface to exchange information, it is an important part of the computer system. It is the interaction and exchange of information between systems and users of media, to realize the human form of information form acceptable to convert between. Standardized design man-machine interface should be the future direction of development; the full expression of a people-oriented design concept, the design process should follow the principles of user-centered, the principle of order, functional principle, the principle of consistency, frequency principle, the principle of the importance and object-oriented principles. 
(3) The issues addressed subsystems. The issue addressed subsystems in the center of decision assistant systems, is a bridge among decision-makers and computers and stored solving resources. issues addressed subsystems through interactive analysis need to be resolved. Issue processing subsystem is the key multi-database integration, processing for computing, integrated data integration model, integrated knowledge inference, establishes a model to solve practical decision-making problems. The issues addressed subsystems consist of problem analysis and solution two parts.

(4) Knowledge management subsystem. Knowledge management subsystem is a platform to achieve knowledge management, based on human intelligence led to information technology as a means of human-machine management system, the crisis management in a variety of knowledge resources for the dynamic integration of knowledge, through knowledge ability to innovate and constantly improve the level of government crisis management decisions. With integrated knowledge resources, promote knowledge transfer, expanding knowledge base and achieve knowledge and human connection and other functions. On the basis of knowledge management subsystem basic framework constructed knowledge management system model including the knowledge collection subsystem, knowledge organization subsystems and knowledge dissemination subsystems.

\section{Conclusion}

The tasks and purpose of public security management is to solve the problem of public crisis, is accompanied by generation of human society existed objectively. With the development of the modern city, the giant city systems become increasingly complex, public crisis events itself and its influence has become more complex, provides a higher demand for the party and the government and various social organizations in crisis management capacity. Crisis management is a highly practical and applied discipline, referring to the successful experience of foreign countries, using government assistant decision-making system, to enhance crisis disposition level, the scientific of decision-making and other aspects has an important practical significance.

\section{Acknowledgment}

This work is supported by social science fund project of Liaoning province (L12BZZ009): Research on management mechanism for urban public crisis.

\section{References}

[1] Naim Kapucu, "Disaster and emergency management systems in urban areas," Cities, vol. 29, no. 1, pp. 41-49, 2012.

[2] J. Wy, "Public crisis management ability," National School of Administration press, 2005.

[3] X. P. Zhang, "A Study on System Construction and Capability Evaluation of Public Crisis Management," Doctor's degree of Dalian University of Technology, 2011.

[4] X. Peng, Y. C. Ren, "Basic Architecture of Government on Urban Emergency Management System," Computer Technology and Development, vol. 23, no. 2, pp. 207-210, 2013.

[5] Y. C. Ren, "Multilayer Architecture on Urban Public Crisis Decision Support System," Advanced Materials Research, vol. 989-994, pp. 5540-5543, 2014.

[6] N. Liu, "Research on public crisis management decision support system," Master's degree of Huazhong Normal University, 2007.

[7]

Baidu Encyclopedia

"Human Machine

Interaction,"

http://baike.baidu.com/link?url=rA-J3EDbgseHeuEWbfaw1rBOjwVfHAEB1ruDmyp4oPYYI0 kbNxqUappOK2tpDgKi0BvjMcCpwyC7y5MOuF4Wv_, 2015-9-5. 